\title{
Parecer da Comissão Técnica Designada pelo Departamento de Arritmias e Eletrofisiologia Clínica da Sociedade Brasileira de Cardiologia (DAEC/SBC)
}

\author{
Fernando E. S. Cruz Fo (Coordenador), A dalberto Lorga, Angelo A. V. de Paola, A yrton K. Peres, \\ Cídio Halperin, Claudio Medeiros, Eduardo B. Sternick, Eduardo Sosa, Jacob A tié, Marcio L. A \\ Fagundes, Reynaldo de Castro Miranda, Sergio Rassi
}

\section{Implante de cardioversor-desfibrilador interno}

No início dos anos 70, foi concebido pelo Dr. Mirowski um cardioversor-desfibrilador implantável (CDI) que permitia, em sua primeira versão, o tratamento elétrico de taquicardia/fibrilação ventriculares. Posteriormente, com o desenvolvimento da tecnologia dessas unidades, seu uso clínico pôde ser iniciado em 1980, obtendo cinco anos após, em 1985, aprovação pelo FDA (Administração de Drogas e Alimentos), órgão regulador americano.

Estatísticas norte-americanas estimam uma incidência de 350.000 a 400.00 indivíduos vítimas de morte súbita ao ano. Embora sem números atualizados, esta morte cardíaca súbita é responsável por 250.000 a 300.00 óbitos anuais no Brasil. Vários estudos clínicos têm demonstrado uma redução concreta dos índices da morte cardíaca súbita relacionadas a taquicardia (TV) e fibrilação ventriculares (FV). Os sistemas CDI de última geração detectam episódios de TV ou FV, utilizando-se algoritmos sistematizados que incluem análise do sinal eletrocardiográfico, início abrupto e critério do aumento da frequiência cardíaca que permitem a correta distinção destas taquiarritmias malignas de outras sem este caráter. A miniaturização das unidades geradoras permitiu o implante peitoral, sem a necessidade de toracotomia, simplificando a técnica e diminuindo as complicações per e pósoperatórias e o seu custo final.

Até o ano de 1997, mais de 30.000CDIs foram implantados anualmente, em vários países do mundo. No Brasil esta técnica já foi incorporada em vários centros, sendo, entretanto, necessária uma maior penetração nas comunidades carentes atendidas pelo Sistema Único de Saúde (SUS).

A incorporação desta nova tecnologia tem se mostrado mais eficaz nos portadores de taquiarritmias malignas quando comparada a outros tipos de terapia utilizadas isoladamente. Com isso a diminuição dos índices de morte cardíaca súbita tem sido registrada e, como conseqüência, preservada a vida de vários indivíduos em fase intelectual e

Correspondência: Fernando E. S. Cruz F ${ }^{\circ}$ - Rua Ipu, 32 - 22281-040 - Rio de Janeiro, RJ social produtivas, evitando uma substancial perda, tanto do ponto de vista humano como social e econômico.

Segundo normas da Sociedade Brasileira de Cardiologia (SBC) através do Departamento de Arritmias e Eletrofisiologia Clínica (DAEC), a indicação, o implante do CDI e o seguimento clínico são da responsabilidade dos membros habilitados do DAEC. O objetivo deste parecer é permitir, desta forma, um melhor gerenciamento das relações custobenefício do CDI.

Assim sendo, a SBC através do DAEC, emite este parecer técnico com todas as diretrizes, visando prestar assessoramento aos órgãos competentes.

\section{Descrição técnica}

A indicação, o implante e o acompanhamento pós-implante do CDI é realizado por equipe multidisciplinar que envolve profissionais da área médica, sob a responsabilidade de um membro habilitado do DAEC, seguindo as seguinte recomendações:

1) as indicações do CDI devem seguir as recomendações do DAEC/SBC publicadas como Consenso nos Arq Bras Cardiol 1995; 64:579-83.

2) $\mathrm{O}$ implante deve ser precedido de avaliação eletrofisiológica seguindo normas de indicação e do parecer técnico do DAEC/SBC publicados nos Arq Bras Cardiol 1995; 64: 149-51 e Arq Bras Cardiol 1995; 64: 585. Esta avaliação deve ser realizada por especialista responsável habilitado pelo DAEC em serviço de eletrofisiologia devidamente autorizado pelo DAEC/SBC.

3) O implante do CDI deve ser conduzido sob a supervisão direta e orientação técnica do eletrofisiologista habilitado do DAEC. O procedimentoé realizado no centro cirúrgico ou na sala de hemodinâmica, utilizando-se radioscopia e todos os cuidados de assepsia e anti-sepsia. A referida sala deve estar equipada com polígrafo e monitor adequados. Durante o implante são avaliados os limiares de comando ventricular e atrial (no caso de estimulação bi-cameral), a medida da onda $\mathrm{R}$, as impedâncias do sistema de estimulação cardíaca e do choque além do limiar de desfibrilação. As propriedades de programação antitaquicardia poderão ser avaliadas no mesmo tempo cirúrgico ou duran- 
te uma avaliação eletrofisiológica posterior. Após o procedimento o paciente deve permanecer internado por 48 a $72 \mathrm{~h}$ com monitorização convencional ou telemetria. Este tempo deve ser prolongado de acordo com a necessidade imposta pela cardiopatia de base ou dos eventos ocorridos após o procedimento.

4) O acompanhamento do paciente submetido ao implante do CDI é da responsabilidade de especialistas do
DAEC do serviço que promoveu o implante ou outorgado a qualquer outro serviço autorizado pelo DAEC.

\section{Agradecimentos}

Aos Drs José Tarcísio M. Vasconcelos e José Carlos Pachón pelas sugestões e participação na elaboração deste parecer. 